\title{
A IMPORTÂNCIA DA ESCUTA E DO DIÁLOGO NA ABORDAGEM AO EXAME CITOPATOLÓGICO: UM RELATO DE EXPERIÊNCIA
}

\section{THE IMPORTANCE OF LISTENING AND DIALOGUE IN THE APPROACH TO CYTOPATHOLOGICAL EXAMINATION: A REPORT OF EXPERIENCE}

Ana Emília Araújo de Oliveira ${ }^{1}$ Gisele Marinho de Farias ${ }^{2}$

\begin{abstract}
RESUMO: INTRODUÇÃO: O Câncer do Colo do Útero é causado pela infecção por alguns tipos do Papilomavírus Humano - HPV. A infecção genital por esse vírus é muito frequente e não causa doença na maioria das vezes. Entretanto, em alguns casos, ocorrem alterações celulares que podem evoluir para o câncer. Alterações que são descobertas no exame preventivo (conhecido também como Exame Citopatológico ou Papanicolau), e são curáveis na quase totalidade dos casos. $O$ Exame é oferecido pelo Sistema Único de Saúde (SUS), como parte da Atenção Primária à Saúde (APS) e das políticas de saúde da mulher, para realizar o rastreamento, o diagnóstico e o tratamento do câncer de colo uterino. Nas Unidades Básicas de Saúde (UBS) os enfermeiros identificam as mulheres para a realização do exame. Desse modo, o profissional de saúde deve estar disposto a ouvir as queixas da mulher, e tentar solucionar alguns problemas através de informações e esclarecimentos. OBJETIVO: Relatar a experiência vivida no atendimento em Saúde da Mulher, na abordagem preventiva ao exame citopatológico. MÉTODO: Este trabalho trata-se de um relato de experiência vivenciado por uma Enfermeira durante o atendimento a mulheres no Centro de Saúde no Município de Campina Grande- PB. RESULTADOS: Através da escuta e do diálogo houve uma aceitação significativa por parte das usuárias no entendimento a todo o processo de realização e da importância do exame. CONCLUSÃO: A importância da escuta, do diálogo e do atendimento humanizado na interação entre profissional e usuárias.
\end{abstract}

Palavras chave: Câncer de Colo Uterino; Saúde da Mulher; Exame Papanicolau.

\footnotetext{
${ }^{1}$ Docente do Curso de Enfermagem da Universidade Estadual da Paraíba - UEPB. Especialista em Educação na Saúde para Preceptores do SUS no Sírio Libanês. Email: anaemiliaoliveira@hotmail.com.

${ }^{2}$ Discente do Curso de Enfermagem da UNINASSAU - CG. Email: gisellemarinho.10@hotmail.com.
} 
ABSTRACT: INTRODUCTION: Cervical câncer is caused by infection with some types of Human Papillomavirus - HPV. Genital infection with this virus is very common and causes no disease most of the time. However, in some cases, cellular changes occur that may progress to cancer. Changes that are discovered on the preventive test (also known as Pap smear) are curable in almost all cases. The Cytopathological Examination is offered by the Unified Health System (SUS), as part of Primary Health Care (PHC) and women's health policies, to perform the screening, diagnosis and treatment of cervical câncer. In the Basic Health Units (BHU) nurses identify women for the exam. Thus, the health professional should be willing to listen to women's complaints, and try to solve some problems through information and clarification. OBJECTIVE: To report the experience lived in Women's Health care, in the preventive approach to cytopathological examination. METHODOLOGY: This paper is a report of the experience lived by a Nurse during the care of women at the Health Center in Campina Grande-PB. RESULTS: Through listening and dialogue there was a significant acceptance by users in understanding the entire process of achievement and the importance of cytological examination CONCLUSION: The importance of listening, dialogue and humanized care in the interaction between professional and users.

Keywords: Cervical Câncer; Women's Health; Pap Smear. 


\section{INTRODUÇÃO}

O Câncer Do Colo Do Útero, também chamado de câncer cervical, é causado pela infecção persistente por alguns tipos do Papilomavírus Humano - HPV (chamados de tipos oncogênicos). A infecção genital por esse vírus é muito frequente e não causa doença na maioria das vezes. Entretanto, em alguns casos, ocorrem alterações celulares que podem evoluir para o câncer. Essas alterações são descobertas facilmente no exame preventivo (conhecido também como Papanicolaou ou Papanicolau), e são curáveis na quase totalidade dos casos. Por isso, é importante a realização periódica desse exame. (INCA, 2015).

O diagnóstico do câncer de colo uterino inclui anamnese, exame físico, testes laboratoriais e imagens radiográficas, principalmente a ressonância magnética (IRM), cuja sensibilidade pode definir melhor o tamanho do tumor e sua extensão. A tomografia por emissão de pósitrons (PET) serve para determinar o grau de envolvimento dos linfonodos na lesão. A remoção de lesões pré-invasivas é feita com base no exame citopatológico, com encaminhamento para colposcopia e biópsia dirigida se for detectada alguma alteração do esfregaço. (BRASIL, 2013).

Em 1984, o Ministério da Saúde elaborou o Programa de Assistência Integral à Saúde da Mulher (PAISM), marcando, sobretudo, uma ruptura conceitual com os princípios norteadores da política de saúde das mulheres e os critérios para eleição de prioridades campo (BRASIL, 1984). O PAISM incorporou como princípios e diretrizes as propostas de descentralização, hierarquização e regionalização dos serviços, bem como a integralidade e a eqüidade da atenção, num período em que, paralelamente, no âmbito do Movimento Sanitário, se concebia o arcabouço conceitual que embasaria a formulação do Sistema Único de Saúde (SUS). O novo programa para a saúde da mulher incluía ações educativas, preventivas, de diagnóstico, tratamento e recuperação, englobando a assistência à mulher em clínica ginecológica, no pré-natal, parto e puerpério, no climatério, em planejamento familiar, 
IST, câncer de colo de útero e de mama, além de outras necessidades identificadas a partir do perfil populacional das mulheres (BRASIL, 2016).

O Exame Citopatológico é oferecido pelo Sistema Único de Saúde (SUS), como parte da Atenção Primária à Saúde (APS) e das políticas de saúde da mulher, para realizar o rastreamento, o diagnóstico e o tratamento do câncer de colo uterino. Nas Unidades Básicas de Saúde (UBS) os enfermeiros identificam as mulheres elegíveis para a realização do exame, por meio de protocolos de priorização de usuárias, e buscam aquelas que não comparecem, oferecendo suporte e informação. Isso tem feito com que o número de exames tenha aumentado em pelo menos cinco pontos percentuais. O nível dos serviços oferecidos pelas UBS é fundamental para a adesão à realização do exame, principalmente em colaboração com a Estratégia Saúde da Família, cujos profissionais estão mais próximos das mulheres (TOMASI et al., 2015).

A Política Nacional de Humanização (PNH) existe desde 2003 para efetivar os princípios do SUS no cotidiano das práticas de atenção e gestão, qualificando a saúde pública no Brasil e incentivando trocas solidárias entre gestores, trabalhadores e usuários. A PNH deve se fazer presente e estar inserida em todas as políticas e programas do SUS. Promover a comunicação entre estes três grupos pode provocar uma série de debates em direção a mudanças que proporcionem melhor forma de cuidar e novas formas de organizar o trabalho (MS, 2016).

É preciso investir numa abordagem mais humanizada para a realização do exame preventivo para esclarecer melhor às mulheres, sobre o processo como um todo, desde a entrevista e exame físico, à coleta do material e orientações finais. A explicação sobre o exame facilita o melhor entendimento do processo sem que haja a construção de opiniões negativas sobre o mesmo (LUCARINI \& CAMPOS, 2017).

Desta forma, este estudo torna-se relevante à medida que busca propor um atendimento humanizado às mulheres, a fim de minimizar algumas dúvidas, angústias e medos através da escuta e do diálogo quanto à importância da realização do exame. O profissional de saúde deve estar disposto a ouvir as queixas da mulher, e tentar solucionar alguns problemas através de informações e esclarecimentos. 


\section{REFERENCIAL TEÓRICO}

Diferentemente dos demais cânceres humanos, o Câncer de Colo Uterino (CCU) é evitável, já que apresenta evolução lenta, com longo período desde o desenvolvimento das lesões precursoras ao aparecimento do câncer (SARAIYA et al., 2002). Apesar de apresentar o maior potencial de prevenção e cura (próximo de 100\%), quando diagnosticado precocemente, o CCU é o segundo tipo de câncer mais freqüente na população feminina, tendo sido responsável por mais de 250.000 mortes em 2005, sendo que $80 \%$ dessas mortes ocorrem nos países em desenvolvimento (ORGANIZACIÓN MUNDIAL DE LA SALUD, 2007).

O grau das lesões que podem ser evidenciadas pelo exame citopatológico é variado, desde alterações celulares de natureza benigna, até atipias celulares, classificadas como escamosas, glandulares ou de origem indefinida, que podem ser neoplásicas ou não. As células escamosas podem significar uma lesão intra-epitelial de baixo grau, lesão intraepitelial de alto grau ou o estágio invasor do câncer de colo uterino. As pacientes com esses dois últimos tipos de lesões devem ser encaminhadas pela Atenção Básica para Unidades de Referência de Média Complexidade, para realizarem imediatamente uma colposcopia, exame do colo uterino, feito pelo ginecologista, usando um colposcópio, que aumenta a visibilidade e soluções para corar as células atacadas pelo HPV (SIQUEIRA et al., 2014).

Em 1984, o Ministério da Saúde elaborou o Programa de Assistência Integral à Saúde da Mulher (PAISM), marcando, sobretudo, uma ruptura conceitual com os princípios norteadores da política de saúde das mulheres e os critérios para eleição de prioridades neste campo (BRASIL, 1984). O PAISM incorporou como princípios e diretrizes as propostas de descentralização, hierarquização e regionalização dos serviços, bem como a integralidade e a eqüidade da atenção, num período em que, paralelamente, no âmbito do Movimento Sanitário, se concebia o arcabouço conceitual que embasaria a formulação do Sistema Único de Saúde (SUS). O novo programa para a saúde da mulher incluía ações educativas, preventivas, de 
diagnóstico, tratamento e recuperação, englobando a assistência à mulher em clínica ginecológica, no pré-natal, parto e puerpério, no climatério, em planejamento familiar, IST, câncer de colo de útero e de mama, além de outras necessidades identificadas a partir do perfil populacional das mulheres (BRASIL, 2016).

O Exame Citopatológico é oferecido pelo Sistema Único de Saúde (SUS), como parte da Atenção Primária à Saúde (APS) e das políticas de saúde da mulher, para realizar o rastreamento, o diagnóstico e o tratamento do câncer de colo uterino. Nas Unidades Básicas de Saúde (UBS) os enfermeiros identificam as mulheres elegíveis para a realização do exame, por meio de protocolos de priorização de usuárias, e buscam aquelas que não comparecem, oferecendo suporte e informação. Isso tem feito com que o número de exames tenha aumentado em pelo menos cinco pontos percentuais. O nível dos serviços oferecidos pelas UBS é fundamental para a adesão à realização do exame, principalmente em colaboração com a Estratégia Saúde da Família, cujos profissionais estão mais próximos das mulheres (TOMASI et al., 2015).

O rastreamento deve ser realizado a partir de 25 anos em todas as mulheres que iniciaram atividade sexual, a cada três anos, se os dois primeiros exames anuais forem normais. (MS, 2016).

O conhecimento sobre a importância do exame citopatológico aumenta com o avançar da idade, tendo o melhor resultado em mulheres jovens. As adolescentes, que geralmente começam a vida sexual muito cedo, com multiplicidade de parceiros, estão expostas aos fatores de risco do câncer de colo uterino, sem que tenham conhecimentos adequados sobre a doença e não tenham o hábito de colocar em prática o exame e as consultas de apresentação dos resultados. A escola, onde se encontra boa parte dessa população, poderia ser acionada com mais ênfase como instância educativa, mas não deixando de lado as ações dos serviços de saúde, principalmente a busca ativa das adolescentes, para incluí-las nas campanhas de vacinação contra o HPV (SILVEIRA et al., 2016).

A Política Nacional de Humanização (PNH) existe desde 2003 para efetivar os princípios do SUS no cotidiano das práticas de atenção e gestão, qualificando a saúde pública no Brasil e incentivando trocas solidárias entre gestores, trabalhadores e usuários. A PNH deve se fazer presente e estar inserida em todas 
as políticas e programas do SUS. Promover a comunicação entre estes três grupos pode provocar uma série de debates em direção a mudanças que proporcionem melhor forma de cuidar e novas formas de organizar o trabalho.A humanização é a valorização dos usuários, trabalhadores e gestores no processo de produção de saúde. Valorizar os sujeitos é oportunizar uma maior autonomia, a ampliação da sua capacidade de transformar a realidade em que vivem, através da responsabilidade compartilhada, da criação de vínculos solidários, da participação coletiva nos processos de gestão e de produção de saúde (MS, 2016).

Produzindo mudanças nos modos de gerir e cuidar, a PNH estimula a comunicação entre gestores, trabalhadores e usuários para construir processos coletivos de enfrentamento de relações de poder, trabalho e afeto que muitas vezes produzem atitudes e práticas desumanizadoras que inibem a autonomia e a corresponsabilidade dos profissionais de saúde em seu trabalho e dos usuários no cuidado de si (MS, 2016).

O "acolhimento" é uma das estratégias criadas para operacionalizar a política de humanização, que se caracteriza como um modo de operar os processos de trabalho em saúde com o intuito de dar atenção a todos/as que procuram os serviços de saúde, ouvindo suas necessidades - escuta qualificada - e assumindo no serviço, uma postura capaz de acolher, escutar e pactuar respostas mais adequadas com os usuários. O acolhimento não é um espaço ou um local, mas uma postura ética, não pressupõe hora ou um profissional específico para fazê-lo, implica compartilhamento de saberes, necessidades, possibilidades, angústias e invenções (BRASIL, 2016).

\section{METODOLOGIA}

Trata-se de um estudo descritivo, tipo relato de experiência, elaborado no contexto do atendimento em Enfermagem em Saúde da Mulher no Centro de Saúde da Liberdade no Município de Campina Grande- PB no período de Março de 2019 até Dezembro de 2019. 
O relato de experiência apresenta reflexão sobre um conjunto de ações que abordam uma situação vivenciada no âmbito profissional de interesse a comunidade científica, sendo assim, uma importante ferramenta da pesquisa descritiva. (CAVALCANTE E LIMA, 2012).

Por se tratar de um relato de experiência, tornou-se dispensável a avaliação deste estudo pelo Comitê de Ética contudo, foi mantido o respeito e anonimato dos participantes em concordância a resolução 466/12 aprovada pelo Conselho Nacional de Saúde.

Este relato de experiência aborda a atuação do profissional de enfermagem no atendimento à Saúde da Mulher, durante a consulta de enfermagem, com enfoque na valorização da escuta e do diálogo, da informação e o esclarecimento de dúvidas frequentes, com relação ao Exame Citopatológico.

O Município de Campina Grande - PB tem uma população de 385.276 habitantes e uma área territorial de $621 \mathrm{~km}^{2}$. É considerado o segundo mais populoso do estado da Paraíba, ficando a $120 \mathrm{~km}$ da capital do estado, João Pessoa (IBGE, 2010).

A rede municipal de saúde é formada por um conjunto de instituições públicas, privadas e filantrópicas, que desenvolve ações assistenciais desde o nível básico até o nível terciário. A Secretaria Municipal de Saúde trabalha com divisão territorial cujos serviços de saúde estão organizados em dez distritos sanitários (DS), com 108 Equipes de Saúde. O Centro de Saúde da Liberdade localiza-se no Bairro da Liberdade, onde faz parte do Distrito Sanitário (DS) XI, atendendo o nível primário e secundário em Saúde, com Equipe Multriprofissional, dentre eles, Profissionais Especialistas.

\section{RELATO DE EXPERIÊNCIA}

O presente relato refere-se à experiência da Enfermeira que atua no Centro de Saúde da Liberdade como profissional desde Março de 2019, a mesma é Docente e Preceptora do Curso de Enfermagem. 
O atendimento é realizado no turno da manhã, de segunda à sexta, com agenda aberta para marcação e atendimento as mulheres para realização do Exame Citopatológico. Em média são realizados 20 exames citopatológicos por semana. O primeiro contato com a profissional de saúde se dá na abordagem prévia para coleta de dados pessoais no preenchimento da ficha "Requisição de exame citopatológico - Colo do útero". Durante o atendimento, a profissional "escuta" e "dialoga" com a usuária, de forma a minimizar algumas dúvidas, angústias e medos quanto à importância da realização do exame. A profissional explica o objetivo e o "PASSO a PASSO "do exame preventivo do câncer de colo de útero (Papanicolaou) que é a principal estratégia para detectar lesões precursoras. Consistindo na escamação de células da superfície externa e interna do colo de útero, com espátula de Ayres e escovinha cervical. A profissional também explica que o material será analisado em laboratório de citopatologia, vindo posteriormente o resultado da coleta.

Observa-se após o diálogo, a aceitação das mulheres em realizar o exame de forma mais confortável e o entendimento delas acerca do objetivo e a importância do mesmo. Na explicação prévia quanto as etapas da coleta, elas relatam que nenhum profissional tinha explicado dessa forma. Ao final do atendimento, foi verificada uma notável mudança na interação das usuárias com a profissional de saúde, comparando-se com o pré - atendimento (abordagem prévia) e após a consulta de enfermagem e término do exame.

No início houve uma certa resistência ao exame, além de muitas dúvidas e medos, no entanto, com a escuta e o diálogo, foi criado um vínculo maior e as usuárias passaram a ser mais assíduas e participativas, indicando a outras mulheres e dessa forma aumentando consideravelmente os atendimentos realizados pela profissional. 


\section{REFERÊNCIAS BIBLIOGRÁFICAS}

BRASIL, M. S. Controle dos cânceres do colo do útero e da mama. $2^{\mathrm{a}}$ ed. Brasília: Ministério da Saúde, 2013.

BRASIL, M. S. Secretaria de Atenção à Saúde, Departamento de Ações Programáticas Estratégicas. Política nacional de atenção integral à saúde da mulher: princípios e diretrizes. Brasília, DF: Ministério da Saúde; 2016.

CAVALCANTE, B. L. L.; LIMA U. T. S. Relato de experiência de uma estudante de Enfermagem.. J Nurs Health, Pelotas (RS) 2012 jan/jun; 1(2):94-103. Disponível em: . Acesso em Outubro de 2019.

IBGE- INSTITUTO BRASILEIRO DE GEOGRAFIA E ESTATÍSTICA, 2010. Pesquisa População Nacional Campina Grande, 2010.

INSTITUTO NACIONAL DE CÂNCER (Brasil). INCA. Diretrizes brasileiras para o rastreamento do câncer do colo do útero. 2. ed. rev. atual. Rio de Janeiro, 2015. 2. ed. rev. atual. Rio de Janeiro, 2015.

LUCARINI ACBS, CAMPOS CJG. Uma análise dos aspectos psicossociais e culturais que permeiam a realização do exame de citologia oncótica. Revista Nursing, 2017.

ORGANIZACIÓN MUNDIAL DE LA SALUD. Control integral del cáncer cervicouterino: guía de práticas esenciales. 2007.

SILVEIRA, N. S. P.; VASCONCELOS, C. T. M.; NICOLAU, I. O.; ORIÁ, M. O . B.; PINHEIRO, P. N. C.; et al. Conhecimento, atitude e prática sobre o exame colpocitológico e sua relação com a idade feminina. Revista Latina-americana de Enfermagem, v. 24, p. 26992706, 2016. Disponível em: < Doi: 10.1590/1518- 8345.0700.2699>

SIQUEIRA, G. S.; OLIVEIRA, V. M. F.; BARRETO, S. M. S. S.; MENEZES, M. O.; SILVA, D. P.; et al. Citopatologia como prevenção do câncer do colo uterino. Cadernos de Graduação Ciências Biológicas e Saúde da Unit, v. 2, n. 1, p. 37- 49, 2014. Disponível em: Acesso em: novembro de 2019.

TOMASI, E.; OLIVEIRA, T. F.; FERANDES, P. A. A. F.; THUMÉ, E.; SILVEIRA, D. S.; et al. Estrutura e processo de trabalho na prevenção do câncer de colo de útero na Atenção Básica à Saúde no Brasil: Programa de Melhoria do Acesso e da Qualidade - PMAQ. Revista Brasileira. 